\title{
Influence of Abutment Materials on the Resultant Color of Heat-pressed Lithium Disilicate Ceramics
}

\author{
Kazuki SHIMADA ${ }^{1,2}$, Motoko NAKAZAWA ${ }^{1}$, Yoshiyuki KAKEHASHI ${ }^{1,2}$ and Hideo MATSUMURA ${ }^{1,2}$ \\ ${ }^{1}$ Department of Crown and Bridge Prosthodontics, Nihon University School of Dentistry, 1-8-13, Kanda-Surugadai, Chiyoda- \\ ku, Tokyo 101-8310, Japan \\ ${ }^{2}$ Division of Advanced Dental Treatment, Dental Research Center, Nihon University School of Dentistry, 1-8-13, Kanda- \\ Surugadai, Chiyoda-ku, Tokyo 101-8310, Japan \\ Corresponding author, Kazuki Shimada E-mail:shimada-kz@dent.nihon-u.ac.jp
}

Received July 28, 2005/Accepted November 11, 2005

\begin{abstract}
The purpose of this study was to evaluate the influence of abutment materials on the color of IPS Empress 2 ceramic coping with different thicknesses. Ceramic coping specimens $(12.0 \times 12.0 \times 0.8-2.0 \mathrm{~mm})$ were fabricated from IPS Empress 2 material (Ingot-100, $\mathrm{n}=5$ /group). Abutment specimens were fabricated from a build-up composite, a gold alloy, or a silverpalladium alloy. Color was evaluated using a colorimeter according to the CIE $\mathrm{L}^{*} \mathrm{a}^{*} \mathrm{~b}^{*}$ system. The $\mathrm{L}^{*} \mathrm{a}^{*} \mathrm{~b}^{*}$ values of the ceramic coping specimens of different thicknesses on each abutment specimen were measured. Following which, the color difference $\left(\Delta E^{*} \mathrm{ab}\right)$ values between the ceramic coping specimens on various abutment specimens were calculated. Significant differences in $\Delta \mathrm{E}^{*} \mathrm{ab}$ value were observed among different abutment specimens at certain ceramic coping thicknesses $(\mathrm{P}<0.05)$. Thus, it was concluded that the color of IPS Empress 2 coping material was influenced significantly by both the thickness of the coping and the color of the abutment material.
\end{abstract}

Key words: Color, Heat-pressed lithium disilicate ceramics, Abutment material

\section{INTRODUCTION}

All-ceramic restorative systems have been used successfully for metal-free restorations in clinical applications. Usually, the full coverage crown is applied to endodontically treated teeth that have been restored with an abutment build-up - and very frequently, these teeth are discolored. Against this background, abutment tooth color is a significant issue with all-ceramic restorative systems ${ }^{1}$. This helps to explain why tooth-colored materials are recommended for the post and core of the all-ceramic system $^{2-5)}$.

High-strength, all-ceramic restorative systems are available as both fixed partial dentures ${ }^{6,7)}$ and opaque all-ceramic copings ${ }^{8-12)}$. The opaque allceramic coping reduces the color influence of the abutment teeth and luting agents. However, it must be noted that the size and volume of component ceramic particles affect the coping opacity, whereby a large number of particles with a size greater than the wavelength of visible light would cause an opaque effect $^{13)}$. To date, all-ceramic restorative systems have been used with discolored abutment teeth to achieve excellent esthetics ${ }^{14)}$.

The IPS Empress 2 system (Ivoclar Vivadent AG, Schaan, Liechtenstein) is a high-strength, all-ceramic restorative system that utilizes heat-pressed ceramics. The strengthening component in the ceramic coping of IPS Empress 2 is lithium disilicate ${ }^{15)}$, and it is more translucent than other high-strength, all- ceramic restorative materials ${ }^{10,11,16)}$. The manufacturer recommended $0.8 \mathrm{~mm}$ for minimum thickness of the IPS Empress 2 ceramic coping. In general, thickness of coping in all-ceramic restorative systems must be greater than that of the layering material on the coping, and the color influence of the coping is predicted to increase with its thickness to yield the final color. However, the effects of coping thickness and abutment materials on the color of IPS Empress 2 have not been established previously.

The purpose of this study was to evaluate the influence of abutment materials on the color of IPS Empress 2 coping in various thicknesses. Color evaluation was based on the Commission Internationale d'Eclairage (CIE) $1976 \mathrm{~L}^{*} \mathrm{a}^{*} \mathrm{~b}^{*}$ uniform color space system using a colorimeter ${ }^{16-33)}$.

\section{MATERIALS AND METHODS}

Table 1 lists the materials that were used in this study. The ceramic coping specimens (ceramic specimen) were fabricated from Ingot-100 of IPS Empress 2 material (E2). This material corresponded to shade A2 of the Vitapan classical shade guide (Vita Zahnfabrick, Bad Säckingen, Germany).

Wax patterns were made with a vinyl polysiloxane impression material (Exafine Putty Type; GC Corp., Tokyo, Japan) using square molds $(12.0 \times 12.0 \mathrm{~mm})$ with a thickness of $0.9,1.1,1.3,1.5$, 1.7, 1.9 , or $2.1 \mathrm{~mm}$.

The wax patterns were invested and heated, and 
Table 1 Materials assessed in this study

\begin{tabular}{|c|c|c|c|c|}
\hline Trade name & Manufacturer & Lot number & Component & Abbreviation \\
\hline $\begin{array}{l}\text { Ceramic material } \\
\text { IPS Empress2 Ingot-100 }\end{array}$ & Ivoclar Vivadent AG & D62511 & $\begin{array}{l}57-80 \mathrm{SiO}_{2}, 0-5 \mathrm{Al}_{2} \mathrm{O}_{3} \\
0.1-6 \mathrm{La}_{2} \mathrm{O}_{3}, 0-5 \mathrm{MgO} \\
0-8 \mathrm{ZnO}, 0-13 \mathrm{~K}_{2} \mathrm{O}, 11-19 \\
\mathrm{Li}_{2} \mathrm{O}, 0-11 \mathrm{P}_{2} \mathrm{O}_{5}, 0-8 \\
\text { additional components } \\
\text { (wt\%) }\end{array}$ & E2 \\
\hline $\begin{array}{l}\text { Abutment materials } \\
\text { Unifil Core }\end{array}$ & GC Corp. & 0312041 & $\begin{array}{l}\text { Fluoroaluminosilicate glass, } \\
\text { Urethane dimethacrylate }\end{array}$ & $\mathrm{COM}$ \\
\hline Casting Gold M.C. Type III & GC Corp. & 0311211 & $\begin{array}{l}\text { 75.0 } \mathrm{Au}, 3.0 \mathrm{Pd}, 5.0 \mathrm{Ag} \\
16.0 \mathrm{Cu}, 1.0 \text { Others (wt\%) }\end{array}$ & GOL \\
\hline Castwell M.C. $12 \%$ Gold & GC Corp. & 0401071 & $\begin{array}{l}12.0 \mathrm{Au}, 20.0 \mathrm{Pd}, 46.0 \mathrm{Ag} \\
20.0 \mathrm{Cu}, 2.0 \text { Others (wt\%) }\end{array}$ & $\mathrm{PD}$ \\
\hline $\begin{array}{l}\text { Try-in agent } \\
\text { Liquid Strip }\end{array}$ & Ivoclar Vivadent AG & F63544 & Glycerine & \\
\hline
\end{tabular}

the ingots pressed into invested forms according to the manufacturer's instructions. The investment ring was then cooled and divested by air abrasion with $50-\mu \mathrm{m}$ aluminum oxide at $0.2 \mathrm{MPa}$ pressure. The specimens were subsequently cleaned with hydrofluoric acid (Invex liquid, Ivoclar Vivadent AG, Schaan, Liechtenstein) in an ultrasonic bath for 10 minutes, and the surface reaction layer was removed with 50$\mu \mathrm{m}$ aluminum oxide at $0.1 \mathrm{MPa}$ pressure.

The ceramic surfaces were ground with 800-grit silicon carbide (SiC) abrasive paper (New Maruto Lap ML-110, Maruto Instrument Co. Ltd., Tokyo, Japan) to obtain thicknesses of $0.8,1.0,1.2,1.4,1.6$, 1.8 , and $2.0 \mathrm{~mm}$. Minimum specimen thickness was set at $0.8 \mathrm{~mm}$ - the lowest thickness value recommended by the manufacturer for the IPS Empress 2 coping. Subsequently, the ceramic specimens were cleaned ultrasonically in distilled water for five minutes and air-dried. Each group consisted of five ceramic specimens.

Abutment specimens were fabricated from a composite build-up material (Unifil Core, GC Corp., Tokyo, Japan), a gold alloy (Casting Gold M.C. Type III, GC Corp., Tokyo, Japan), and a silverpalladium alloy (Castwell M.C. 12\% Gold, GC Corp., Tokyo, Japan).

The composite build-up material was spatulated according to the manufacturer's instructions, filled into a silicone mold $(12.0 \times 12.0 \times 7.0 \mathrm{~mm})$, covered with a glass plate, and exposed using a photocuring unit (Optilux 501, Kerr Corp., Orange, Calif., USA) for 90 seconds on each side. The surface was then ground with 800-grit silicon carbide ( $\mathrm{SiC}$ ) abrasive paper (New Maruto Lap ML-110) to a thickness of
$6.0 \mathrm{~mm}$ (COM). As for the metallic specimens, they were fabricated from wax patterns made using a silicone mold $(12.0 \times 12.0 \times 1.5 \mathrm{~mm})$. They were composed of either gold or silver-palladium alloy, and the casting surfaces were ground with 800-grit silicon carbide ( $\mathrm{SiC}$ ) abrasive paper (New Maruto Lap ML110 ) to a thickness of $1.2 \mathrm{~mm}$ (GOL and PD, respectively).

Color evaluation was based on the CIE 1976 $\mathrm{L}^{*} \mathrm{a}^{*} \mathrm{~b}^{*}$ uniform color space system. The $\mathrm{L}^{*} \mathrm{a}^{*} \mathrm{~b}^{*}$ values of the ceramic specimens - of different thicknesses - placed on each abutment specimen were measured. Try-in agent (Liquid Strip, Ivoclar Vivadent AG, Schaan, Liechtenstein) was applied to minimize the influence of light refraction by eliminating any air between the ceramic specimen and abutment specimen ${ }^{22)}$, which might otherwise interfere with accurate color measurement (Fig. 1). Three points on each specimen were measured using the 'Analyze mode' of the colorimeter (ShadeEye NCC, Shofu Inc., Kyoto, Japan), and the $\mathrm{L}^{*} \mathrm{a}^{*} \mathrm{~b}^{*}$ values recorded accordingly (Fig.1). In addition, the color difference $\left(\Delta \mathrm{E}^{*} \mathrm{ab}\right)$ values of the ceramic specimens on different abutment specimens were calculated as follows:

$$
\Delta \mathrm{E}^{*} \mathrm{ab}=\left\{\left(\Delta \mathrm{L}^{*}\right)^{2}+\left(\Delta \mathrm{a}^{*}\right)^{2}+\left(\Delta \mathrm{b}^{*}\right)^{2}\right\}^{1 / 2}
$$

where $\Delta \mathrm{L}^{*}=\mathrm{L}^{*}{ }_{1}-\mathrm{L}^{*}{ }_{0}, \Delta \mathrm{a}^{*}=\mathrm{a}^{*}{ }_{1}-\mathrm{a}^{*}{ }_{0}$, and $\Delta \mathrm{b}^{*}=$ $\mathrm{b}^{*}{ }_{1}-\mathrm{b}{ }_{0}$

Two-way analysis of variance (ANOVA) and Tukey-HSD test $(\mathrm{P}<0.05)$ were used to analyze the differences in $\Delta \mathrm{L}^{*}, \Delta \mathrm{a}^{*}, \Delta \mathrm{b}^{*}$, and $\Delta \mathrm{E}^{*}$ ab values of the ceramic specimens placed on each abutment specimen (hereinafter referred to as COM-GOL, COM-PD, 


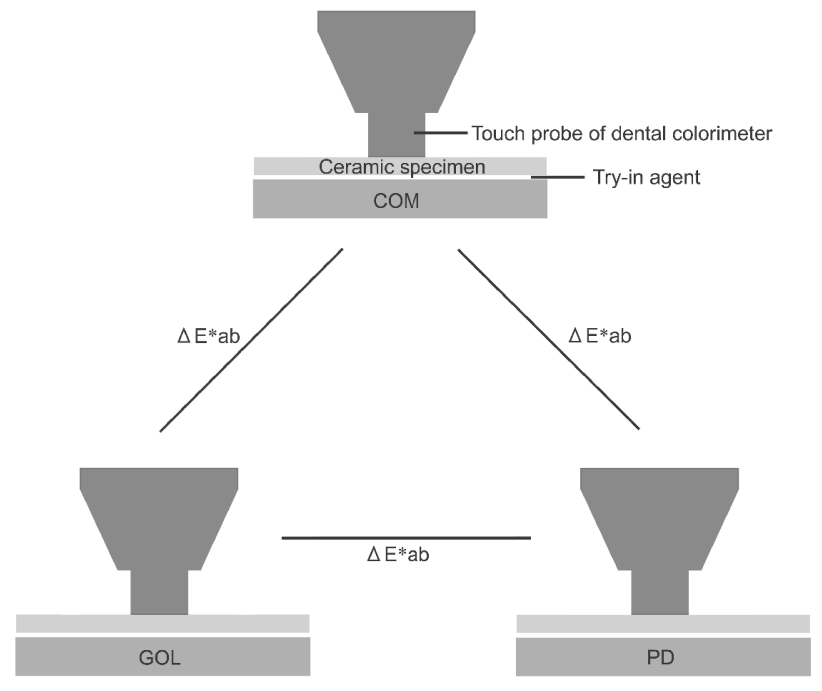

Fig. 1 Measurement of $\Delta \mathrm{E}^{*} \mathrm{ab}$ values of ceramic specimens on different abutment specimens. and GOL-PD). All statistical analyses were performed using SPSS statistical software package, version 12.0 (SPSS Inc., Chicago, Ill, USA).

\section{RESULTS}

The $\mathrm{L}^{*} \mathrm{a} \mathrm{b}^{*}$ values of abutment specimens are summarized in Table 2. Two-way ANOVA revealed that $\Delta \mathrm{L}^{*}, \Delta \mathrm{a}^{*}$, and $\Delta \mathrm{b}^{*}$ values were influenced by both abutment material $(\mathrm{F}=12.4,1060.3,49.1, \mathrm{p}=0.001$, $0.001,0.001)$ and thickness $(\mathrm{F}=4.2,158.2,14.9, \mathrm{p}=$ $0.01,0.001,0.001$ ) (Tables 3-5). An interaction was not indicated only $\Delta \mathrm{L}^{*}$ values $(\mathrm{F}=0.93, \mathrm{p}=0.524)$.

Table 2 The $\mathrm{L}^{*} \mathrm{a} \mathrm{b}^{*}$ values of the abutment specimens

\begin{tabular}{ccccc}
\hline Abutment specimen & \multicolumn{2}{c}{$\mathrm{L}^{*}$} & $\mathrm{a}^{*}$ & \multicolumn{2}{c}{$\mathrm{b}^{*}$} \\
\hline COM & $71.2(0.1)$ & $2.5(0.1)$ & $12.9(0.1)$ \\
GOL & $74.2(0.1)$ & $7.1(0.1)$ & $17.1(0.0)$ \\
PD & $72.2(0.1)$ & $1.7(0.1)$ & $8.1(0.1)$ \\
\hline
\end{tabular}

The s.d. values are shown in parentheses.

Table 3 The $\Delta \mathrm{L}^{*}$ values of the ceramic specimens on different abutment specimens

\begin{tabular}{cccccccc}
\hline Thickness of ceramic specimen & 0.8 & 1.0 & 1.2 & 1.4 & 1.6 & 1.8 & $2.0 \mathrm{~mm}$ \\
\hline \multirow{2}{*}{ COM-GOL } & 0.5 & 0.8 & 0.6 & 0.4 & 0.7 & 0.4 & 0.4 \\
& $(0.8)$ & $(0.6)$ & $(0.2)$ & $(0.4)$ & $(0.1)$ & $(0.1)$ & $(0.5)$ \\
COM-PD & 1.1 & 1.1 & 1.3 & 0.9 & 0.9 & 0.4 & 0.9 \\
& $(0.4)$ & $(0.6)$ & $(0.2)$ & $(0.4)$ & $(0.2)$ & $(0.3)$ & $(0.3)$ \\
GOL-PD & 0.7 & 1.0 & 0.6 & 0.6 & 0.2 & 0.4 & 0.4 \\
& $(0.4)$ & $(0.7)$ & $(0.3)$ & $(0.3)$ & $(0.1)$ & $(0.2)$ & $(0.3)$ \\
\hline
\end{tabular}

The s.d. values are shown in parentheses.

Table 4 The $\Delta \mathrm{a}^{*}$ values of the ceramic specimens on different abutment specimens

\begin{tabular}{cccccccc}
\hline Thickness of ceramic specimen & 0.8 & 1.0 & 1.2 & 1.4 & 1.6 & 1.8 & $2.0 \mathrm{~mm}$ \\
\hline \multirow{2}{*}{ COM-GOL } & 3.4 & 2.4 & 2.0 & 1.6 & 1.1 & 1.1 & 0.7 \\
& $(0.2)$ & $(0.3)$ & $(0.1)$ & $(0.3)$ & $(0.1)$ & $(0.2)$ & $(0.1)$ \\
COM-PD & 0.2 & 0.3 & 0.4 & 0.4 & 0.5 & 0.2 & 0.4 \\
& $(0.1)$ & $(0.2)$ & $(0.0)$ & $(0.2)$ & $(0.1)$ & $(0.1)$ & $(0.1)$ \\
GOL-PD & 3.2 & 2.7 & 2.4 & 2.0 & 1.6 & 1.3 & 1.1 \\
& $(0.0)$ & $(0.2)$ & $(0.1)$ & $(0.2)$ & $(0.1)$ & $(0.3)$ & $(0.1)$ \\
\hline
\end{tabular}

The s.d. values are shown in parentheses.

Table 5 The $\Delta \mathrm{b}^{*}$ values of the ceramic specimens on different abutment specimens

\begin{tabular}{cccccccc}
\hline Thickness of ceramic specimen & 0.8 & 1.0 & 1.2 & 1.4 & 1.6 & 1.8 & $2.0 \mathrm{~mm}$ \\
\hline \multirow{2}{*}{ COM-GOL } & 1.2 & 0.5 & 0.1 & 0.2 & 0.3 & 0.2 & 0.4 \\
& $(0.7)$ & $(0.6)$ & $(0.1)$ & $(0.1)$ & $(0.2)$ & $(0.2)$ & $(0.3)$ \\
COM-PD & 1.5 & 1.2 & 1.4 & 1.3 & 1.2 & 0.7 & 1.1 \\
& $(0.5)$ & $(0.5)$ & $(0.3)$ & $(0.2)$ & $(0.2)$ & $(0.3)$ & $(0.4)$ \\
GOL-PD & 2.7 & 1.6 & 1.5 & 1.4 & 0.8 & 0.6 & 0.7 \\
& $(0.4)$ & $(1.0)$ & $(0.2)$ & $(0.2)$ & $(0.4)$ & $(0.1)$ & $(0.4)$ \\
\hline
\end{tabular}

The s.d. values are shown in parentheses. 


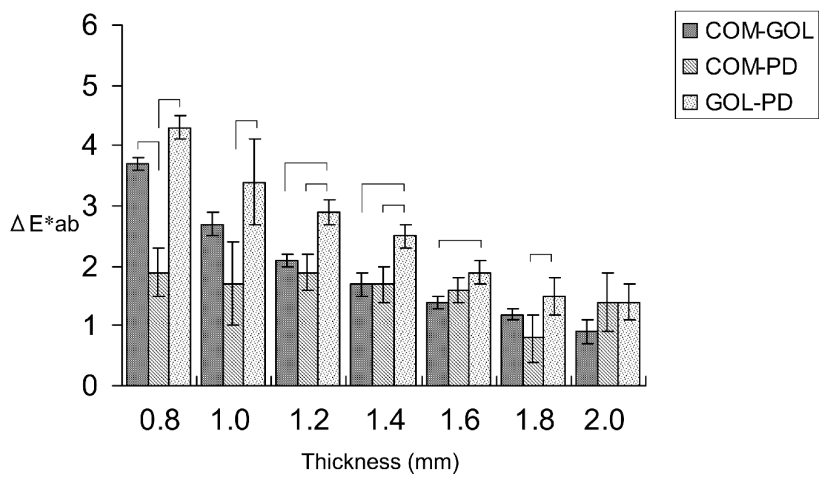

Fig. 2 The $\Delta \mathrm{E}^{*} \mathrm{ab}$ values of ceramic specimens on different abutment specimens. Horizontal bars indicate significant differences $(\mathrm{p}<0.05)$

Two-way ANOVA run on $\Delta \mathrm{E}^{*}$ ab values revealed that the interaction between abutment material and thickness $(\mathrm{F}=8.7, \mathrm{p}=0.001)$ was significant, and that the $\Delta \mathrm{E}^{*}$ ab values were affected by both the type of abutment material $(\mathrm{F}=64.2, \mathrm{p}=0.001)$ and thickness $(\mathrm{F}=65.8 \mathrm{p}=0.001)$. Therefore, the $\Delta \mathrm{E}^{*} \mathrm{ab}$ values were further analyzed by one-way ANOVA and Tukey-HSD test $(\mathrm{P}<0.05)$ (Fig. 2).

At $0.8 \mathrm{~mm}$ thickness, the $\Delta \mathrm{E}^{*}$ ab values of COM-GOL and GOL-PD were greater than that of COM-PD. At 1.0 and $1.8 \mathrm{~mm}$ thicknesses, GOL-PD was greater than COM-PD. At 1.2 and $1.4 \mathrm{~mm}$ thicknesses, GOL-PD was greater than COM-GOL and COM-PD. At $1.6 \mathrm{~mm}$ thickness, GOL-PD was greater than COM-GOL. At $1.0 \mathrm{~mm}$ thickness or more, the $\Delta \mathrm{E}^{*}$ ab values were not significantly different between COM-GOL and COM-PD. At $2.0 \mathrm{~mm}$ thickness, there were no significant differences.

\section{DISCUSSION}

Recently, all-ceramic restorations have led to a number of advances in reconstructive dentistry. Without a supporting metal substructure, the main breakthrough has been in achieving light scattering and transmission that gives the illusion of natural teeth $^{1)}$. In particular, opaqueness can be prevented in the cervical area such that no metal color is visible even if marginal gingival recession occurs. Moreover, leveraging on the development of adhesive techniques, inlay, onlay and laminate veneer restorations have become possible. Likewise, fixed partial dentures have been realized through the development of high-strength, all-ceramic restorative systems ${ }^{6,7)}$.

With ceramic copings, one additional characteristic is opacity ${ }^{9-12)}$. However, the influence of the color of abutment teeth on the E2 system has not been established previously. Therefore, we investigated this aspect of influence on E2 by measuring its $\mathrm{L}^{*} \mathrm{a}^{*} \mathrm{~b}^{*}$ values $^{16-32)}$ with a reliable hand-held color- imeter $^{23-25,30,32)}$. Following which, the influence of abutment material on the color of E2 of various thicknesses was evaluated by calculating and comparing the $\Delta \mathrm{E}^{*} \mathrm{ab}, \Delta \mathrm{L}^{*}, \Delta \mathrm{a}^{*}$, and $\Delta \mathrm{b}^{*}$ values.

Among the $\Delta \mathrm{L}^{*}$ values, only thicknesses of 1.2 and $1.6 \mathrm{~mm}$ revealed significant differences. On the other hand, for $\Delta \mathrm{a}^{*}$ values, those of COM-PD were consistently smaller than COM-GOL and GOL-PD at all thickness. For $\Delta b^{*}$ values, GOL-PD was significantly larger than COM-GOL up to the thickness of $1.8 \mathrm{~mm}$. Based on the results of this study, it was found that the condition of each abutment tooth exerted little influence on lightness. On the other hand, the influence on chroma and hue was substantial. In particular, GOL was greater than COM and $\mathrm{PD}$ in the $\mathrm{a}^{*}$ (red-green) value of the abutment specimen. Further, the $b^{*}$ value (yellow-blue) of PD influenced the chroma and hue because the $b^{*}$ value was smaller than COM and GOL.

In the $\Delta \mathrm{E}^{*}$ ab formula, brightness, chroma, and hue are of the same scale. However, the concept of $\Delta \mathrm{E}^{*}{ }_{00}$ (CIEDE 2000) that includes weighting functions on chroma and hue has been introduced in recent years ${ }^{33)}$.

Alternatively, the acceptable $\Delta \mathrm{E}^{*}$ ab value according to the United States Public Health Service (USPHS) criteria is $3.7^{17)}$, while other sources recommend values ranging from 1.0 to $3.7^{18-32)}$. Then, based on an evaluation according to stages ${ }^{16)}$, the clinically satisfactory value was reported to be 2.0 . Therefore, in this study, 2.0 was adopted as the acceptable $\Delta \mathrm{E}^{*}$ ab value.

In the current study, no significant differences in $\Delta \mathrm{E}^{*} \mathrm{ab}$ value were noted at $2.0 \mathrm{~mm}$ thickness. Further, it was at the thickness of $1.6 \mathrm{~mm}$ that the $\Delta \mathrm{E}^{*} \mathrm{ab}$ value revealed 2.0 or less.

For high-strength, all-ceramic restorative systems, the strengthening components of the ceramic copings are alumina, zirconium oxide, and lithium disilicate $^{10,15)}$. In the case of $\mathrm{E} 2$, the strengthening component is lithium disilicate, with a particle size of 0.5 to $4.0 \mu \mathrm{m}$ present at a volume of 65 to $75 \%{ }^{15)}$. The microstructure of E2 also contains lithium orthophosphate crystals. It should be noted that the color and translucency of ceramics are influenced by the refractive index difference between the particle and coping matrix, as well as by the pigments in the material $^{10,13)}$. This is because these factors influence the diffusion and scattering of light. Wavelength of visible light is 0.4 to $0.7 \mu \mathrm{m}$, and ceramic materials can contain particles that are larger or smaller than this wavelength. Refraction and reflection occur infinitely on the surfaces of particles that are larger than the wavelength of light, thereby causing the light to diffuse. A similar phenomenon occurs as a result of the porosity of ceramic materials. The greater the refractive index difference between particle size and ceramic matrix, the greater the refrac- 
tion and reflection of light, which leads to an opaque effect in ceramic materials ${ }^{10,13)}$.

The contrast ratio method is commonly used to compare relative translucency ${ }^{9)}$. Contrast ratio is measured based on the luminous reflectance $(\mathrm{Y})$ of a specimen on black ( $\mathrm{Yb}$ ) and white backings ( $\mathrm{Yw}$ ) to give a $\mathrm{Yb} / \mathrm{Yw}$ value ranging from 0.0 (transparent) to 1.0 (opaque) ${ }^{10,11,15)}$. According to Höland et $a l^{15)}$, the contrast ratio of the coping material of E2 at a thickness of $1.0 \mathrm{~mm}$ was 0.55 . As for Heffernan et $a l .{ }^{10)}$, the contrast ratio of the ceramic coping of $\mathrm{E} 2$ at a thickness of $0.8 \mathrm{~mm}$ was reported to be 0.72 . In a subsequent study, when a layering material of 0.7 $\mathrm{mm}$ thickness was applied (definitive thickness: 1.5 $\mathrm{mm}$ ), the contrast ratio was reported to be 0.78 before grazing and 0.77 after grazing ${ }^{11)}$. By these reports, color of the post and core was found to have a slight influence on E2 when the ceramic coping thickness was $0.8 \mathrm{~mm}$ or more.

In the present study, ceramic copings of E2 of $1.6 \mathrm{~mm}$ thickness or more prevented the evaluated abutment materials to exert any clinically unacceptable color influence. However, the layering material - like a color porcelain - is necessary on a ceramic coping. Moreover, the amount of abutment tooth reduction may pose a problem too. Taken together, it is almost impossible to have a setting of $1.6 \mathrm{~mm}$ thickness or more for ceramic copings. For the IPS Empress 2 ceramic coping, minimum thickness of 0.8 $\mathrm{mm}$ recommended by the manufacturer is appropriate. On this note, when selecting the abutment material, it is necessary to consider its influence on the final color as $\mathrm{E} 2$ is placed after the tooth is endodontically treated.

\section{ACKNOWLEDGEMENTS}

This study was supported by the Nihon University Research Grant for Assistants and Young Researchers (2004), Nihon University Individual Research Grant for (2005), and Grant from Dental Research Center, Nihon University School of Dentistry (2004). It was presented at the 83rd General Session of the International Association of Dental Research, March 2005, Baltimore, Maryland (supported by the Satoh Research Fund of Nihon University School of Dentistry (2004)).

\section{REFERENCES}

1) McLean JW. New dental ceramics and esthetics. J Esthet Dent 1995; 7: 141-149.

2) Kakehashi $Y$, Lüthy $H$, Naef $R$, Wohlwend $A$, Schärer P. A new all-ceramic post and core system: Clinical, technical, and in vitro results. Int J Periodontics Restorative Dent 1998; 18: 587-593.

3) Ahmad I. Zirconium oxide post and core system for the restoration of an endodontically treated incisor.
Pract Periodontics Aesthet Dent 1999; 11: 197-204, 206.

4) Carossa S, Lombardo S, Pera P, Corsalini M, Rastello ML, Preti G. Influence of post and cores on light transmission through different all-ceramic crowns: Spectrophotometric and clinical evaluation. Int $J$ Prosthodont 2001; 14: 9-14.

5) Al-harbi F, Nathanson D. In vitro assessment of retention of four esthetic dowels to resin core foundation and teeth. J Prosthet Dent 2003; 90: 547-555.

6) Stumpel LJ 3rd, Haechler WH. The all-ceramic cantilever bridge: A variation on a theme. Compend Contin Educ Dent 2001; 22: 45-50, 52, 54.

7) McLaren EA, Terry DA. CAD/CAM systems, materials, and clinical guidelines for all-ceramic crowns and fixed partial dentures. Compend Contin Educ Dent 2002; 23: 637-654.

8) Magne P, Magne M, Belser U. The esthetic width in fixed prosthodontics. J Prosthodont 1999; 8: 106-118.

9) Antonson SA, Anusavice KJ. Contrast ratio of veneering and core ceramics as a function of thickness. Int $\mathrm{J}$ Prosthodont 2001; 14: 316-320.

10) Heffernan MJ, Aquilino SA, Diaz-Arnold AM, Haselton DR, Stanford CM, Vargas MA. Relative translucency of six all-ceramic system. Part I: Core materials. J Prosthet Dent 2002; 88: 4-9.

11) Heffernan MJ, Aquilino SA, Diaz-Arnold AM, Haselton DR, Stanford CM, Vargas MA. Relative translucency of six all-ceramic system. Part II: Core and veneer materials. J Prosthet Dent 2002; 88: 10-15.

12) Webber B, McDonald A, Knowles J. An in vitro study of the compressive load at fracture of Procera AllCeram crowns with varying thickness of veneer porcelain. J Prosthet Dent 2003; 89: 154-160.

13) Clarke FJ. Measurement of color of human teeth. In: Proceedings of the First International Symposium on Ceramics, McLean JW (ed), Quintessence Publishing Co. Inc., Chicago, 1983, pp.441-490.

14) Hager B, Oden A, Andersson B, Andersson L. Procera AllCeram laminates: A clinical report. J Prosthet Dent 2001; 85: 231-232.

15) Höland W, Schweiger M, Frank M, Rheinberger V. A comparison of the microstructure and properties of the IPS Empress ${ }^{\circledR} 2$ and the IPS Empress ${ }^{\circledR}$ glass-ceramics. J Biomed Mater Res 2000; 53: 297-303.

16) Barath VS, Faber FJ, Westland S, Niedermeier W. Spectrophotometric analysis of all-ceramic materials and their interaction with luting agent and different backgrounds. Adv Dent Res 2003; 17: 55-60.

17) Johnston WM, Kao EC. Assessment of appearance match by visual observation and clinical colorimetry. J Dent Res 1989; 68: 819-822.

18) Balderamos LP, O’Keefe KL, Powers JM. Color accuracy of resin cements and try-in pastes. Int $J$ Prosthodont 1997; 10: 111-115.

19) Hosoya Y. Five-year color changes of light-cured resin composites: Influence of light-curing times. Dent Mater 1999; 15: 268-274.

20) Hersek N, Canay S, Uzun G, Yildiz F. Color stability of denture base acrylic resins in three food colorants. J Prosthet Dent 1999; 81: 375-379. 
21) Heydecke G, Zhang F, Razzog ME. In vitro color stability of double-layer veneers after accelerated aging. J Prosthet Dent 2001; 85: 551-557.

22) Buchalla W, Attin T, Hilgers RD, Hellwig E. The effect of water storage and light exposure on the color and translucency of a hybrid and a microfilled composite. J Prosthet Dent 2002; 87: 264-270.

23) Koishi Y, Tanoue N, Atsuta M, Matsumura H. Influence of visible-light exposure on color stability of current dual-curable luting composites. J Oral Rehabil 2002; 29: 387-393.

24) Wee AG, Monaghan P, Johnston WM. Variation in color between intended matched shade and fabricated shade of dental porcelain. J Prosthet Dent 2002; 87: 657666.

25) Tung FF, Goldstein GR, Jang S, Hittelman E. The repeatability of an intraoral dental colorimeter. J Prosthet Dent 2002; 88: 585-590.

26) Douglas RD, Brewer JD. Variability of porcelain color reproduction by commercial laboratories. J Prosthet Dent 2003; 90: 339-346.

27) Dozić A, Kleverlaan CJ, Meegdes M, van der Zel J, Feilzer AJ. The influence of porcelain layer thickness on the final shade of ceramic restorations. J Prosthet Dent 2003; 90: 563-70.
28) Koutayas SO, Kakaboura A, Hussein A, Strub JR. Colorimetric evaluation of the influence of five different restorative materials on the color of veneered densely sintered alumina. J Esthet Restor Dent 2003; 15: $353-361$.

29) Arikawa H, Kanie T, Fujii K, Ban S, Honma T. Optical and color stabilities of paint-on resins for shade modification of restorative resins. Dent Mater J 2004; 23: $155-160$.

30) Okamura M, Chen KK, Kakigawa H, Kozono Y. Application of alumina coping to porcelain laminate veneered crown. Part 1: Masking ability for discolored teeth. Dent Mater J 2004; 23: 180-183.

31) Nakamura T, Tanaka H, Kawamura Y, Wakabayashi K. Translucency of glass-fibre-reinforced composite materials. J Oral Rehabil 2004; 31: 817-821.

32) Tanoue N, Koishi Y, Yanagida H, Atsuta M, Shimada $\mathrm{K}$, Matsumura H. Color stability of acrylic resin adhesive with different initiation modes. Dent Mater J 2004; 23: 368-372.

33) Lee YK, Powers JM. Comparison of CIE Lab, CIEDE 2000, and DIN 99 color differences between various shades of resin composites. Int J Prosthodont 2005; 18 : 150-155. 